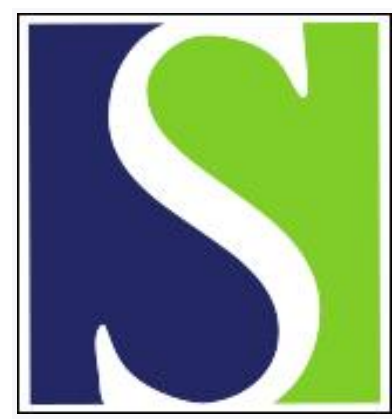

Scand J Work Environ Health 2012;38(2):163-170

https://doi.org/10.5271/sjweh.3262

Published online: 23 Nov 2011, Issue date: Mar 2012

A case-crossover study of work-related acute traumatic hand injuries in the People's Republic of China

by Jin K, Lombardi DA, Courtney TK, Sorock GS, Li M, Pan R, Wang X, Lin J, Liang Y, Perry MJ

Affiliation: Department of Occupational Health, School of Public Health, Fudan University, 138 Yi Xue Yuan Road, Box 288\#, Shanghai, People's Republic of China, 200032. zhkjin@fudan.edu.cn

The following articles refer to this text: 2014;40(2):146-155; 2017;43(3):217-225; 2017;43(3):191-195

Key terms: acute traumatic hand injury; case-crossover study; China; hand injury; hospitalization; occupational injury epidemiology; People Republic of China; relative risk; relative risk; reliability; transient risk factor

This article in PubMed: www.ncbi.nlm.nih.gov/pubmed/22113649 


\title{
A case-crossover study of work-related acute traumatic hand injuries in the People's Republic of China
}

\author{
by Kezhi Jin, PhD, 1, 2, 3, 4, 5 David A Lombardi, PhD,4, 5 Theodore K Courtney, MS, CSP, 5 Gary S Sorock, \\ PhD, ${ }^{6}$ Mingqiang Li, MSc, ${ }^{7}$ Rong Pan, MPH, ${ }^{7}$ Xin Wang, MD, ${ }^{9}$ Jie Lin, MSc, ${ }^{9}$ Youxin Liang, MD, PhD, ${ }^{1,2,3}$ \\ Melissa J Perry, $S c D^{5,10}$
}

\begin{abstract}
Jin K, Lombardi DA, Courtney TK, Sorock GS, Li M, Pan R, Wang X, Lin J, Liang Y, Perry MJ. A case-crossover study of work-related acute traumatic hand injuries in the People's Republic of China. Scand J Work Environ Health. 2012;38(2):163-170. doi:10.5271/sjweh.3262
\end{abstract}

\begin{abstract}
Objective The aim of this study was to quantify potential transient risk factors for occupational acute hand injury among hospitalized workers in the People's Republic of China (PRC).

Methods Participants were recruited from 11 medical facilities in 3 cities of the PRC. A face-to-face interview was used to collect information on the occurrence of 8 potential risk factors within a 90 -minute time period before an acute traumatic hand injury and during a control period within the month before the injury. The reliability of reporting transient risk factors was assessed, and a case-crossover design was used to estimate the injury incidence risk ratio (IRR) of each risk factor.
\end{abstract}

Results In total,703 hospitalized workers completed the interview (527 male, 176 female), with a mean age of 31.8 [standard deviation (SD) 10.3] years. The median time interval between injury and interview was four days. Thirty percent of participants had a crush injury and $25.7 \%$ had an amputation. Using malfunctioning machinery/ tools/material, performing a task with a different method, working overtime, and wearing gloves were found to have good reliability in test-retest examination [intra-class correlation coefficient (ICC) $>0.9$ ]. The IRR of a hand injury were markedly increased while using malfunctioning machinery/tools/material $[110.4,95 \%$ confidence interval $(95 \%$ CI $) 97.4-125.2]$, performing a task with a different method than usual $(84.3,95 \%$ CI $67.7-105.1)$, or being distracted (69.6, 95\% CI 57.9-83.7). Gender and size of company were associated with differences in glove usage.

Conclusions The results suggest the importance of transient, potentially modifiable factors in the etiology of occupational acute hand injury in the PRC. Regular maintenance of machinery/tools, work practice controls, and avoiding distractions should be priorities for reducing the risk of occupational acute hand injuries.

Key terms hospitalization; occupational injury epidemiology; relative risk; reliability; transient risk factor.

Economic globalization has further accelerated already booming labor-intensive industries in developing countries/regions. The hand is identified as the most injured body part for workers not only in developed countries (eg, United States) (1) but also in developing countries (eg, Turkey) (2). The prevalence of work-related hand injury was reported to be $13.6 \%$ in a large hospital in
Pakistan (3). A very interesting observation was that hand injuries increased even as the total rate of occupational accidents decreased in a developing region (4).

Hand injuries are common in the People's Republic of China (PRC) (5). Data from epidemiological studies on hand injuries published in Chinese from 1994-2005 show that between $23-54 \%$ of all visits to emergency

1 Department of Occupational Health, School of Public Health, Fudan University, Shanghai, People's Republic of China.

2 Key Laboratory of Public Health Safety, Ministry of Education, Shanghai, People's Republic of China.

3 WHO Collaborating Center for Occupational Health, Shanghai, People's Republic of China.

4 Center for Injury Epidemiology, Liberty Mutual Research Institute for Safety, Hopkinton, MA, USA.

5 Department of Environmental Health, Harvard School of Public Health, Boston, MA, USA.

6 Springfield Hospital Center, Sykesville, MD, USA.

7 Liuzhou Municipal Center for Diseases Control and Prevention, Liuzhou, People's Republic of China.

8 Ningbo No. 6 Hospital, Ningbo, People's Republic of China.

9 Wuxi Municipal Center for Diseases Control and Prevention, Wuxi, People's Republic of China.

10 George Washington University, School of Public Health and Health Services, Washington, DC, USA.

Correspondence to: Dr Kezhi Jin, 138 Yi Xue Yuan Road, Box 288\#, Shanghai, PRC, 200032. [E-mail: zhkjin@fudan.edu.cn] 
departments were for hand injuries (5). A search of the Chinese core journals from 1996-2006 using the China Academic Journals fulltext database (CAJ) (the largest database of academic journals published in Chinese) and the key words "hand injury" produced 90 papers on hand injury. Of the 13 epidemiological studies, only one examined risk factors for work-related traumatic hand injury using an analytic study design (ie, case-control), while the others were primarily descriptive studies. The case-control study evaluated fixed risk factors for hand injury that are commonly studied, such as employment type, age, and gender (6). PubMed was also searched for papers on hand injury among Chinese, published in English during the same period. Fifty-six papers were identified; none quantified risk factors for occupational hand injury.

In the current study, we evaluated several potentially modifiable transient risk factors for acute hand injury (eg, using malfunctioning equipment and being distracted), rather than fixed risk factors (age and industry type). These transient factors have not been well studied in the PRC. The case-crossover study design provides a design approach that can be used to study transient risk factors for acute events (7). One important feature of the case-crossover design is that each participant serves as his/her own control canceling the potential confounding due to differences between individuals, such as age, gender, occupation, or task experience. However, recall bias can occur if interview data is involved. For more information on limitations and study planning using case-crossover design, please see Maclure \& Mittleman (8). This design has been used to study occupational injuries in the US by Lombardi et al (9) and Sorock et al $(10,11)$, who identified modifiable transient risk factors for acute hand injuries.

In the Sorock et al (11) and Lombardi et al (9) studies, performing unusual work tasks, being distracted or rushed, equipment or tool malfunction, new work methods, or not wearing gloves were significantly associated with the occurrence of an acute work-related hand injury. A similar design was adopted to study occupational hand injuries among 192 workers from Hong Kong. Chow et al (12) reported malfunctioning equipment/materials, different work methods, performing unusual work tasks, working overtime, feeling ill, being distracted, and rushing as transient risk factors for hand injury occurrence. However wearing gloves was not a significant protective factor.

To evaluate the US hand injury protocol for use with injured workers in the PRC, a pilot study was conducted with the study materials translated into Chinese (13). This study assessed the feasibility of participant recruitment, standardized informed consent procedures, cross translation of the Hand Injury Study questionnaire into Chinese, and interview quality control. Areas of improvement in study procedures identified from the pilot study, such as data collection efficiency and quality, were incorporated into the final study questionnaire. For example the data collection protocol in the final study used non-physician interviewers and required intensive interviewer training compared to the original design in the pilot study. Key aspects of the study protocol and results describing the basic characteristics of the study population and injury patterns have been reported elsewhere (5). The purpose of the current report is to provide analytic data on transient risk factors associated with work-related acute traumatic hand injury among hospitalized workers in the PRC.

\section{Methods}

\section{Participant selection}

Between October 2004-2006, study subjects were recruited from patients admitted for treatment for a sudden-onset, traumatic injury to the fingers, hand, or wrist in two hand-surgery hospitals and nine general hospitals in three industry-concentrated cities: Ningbo (Zhejiang Province), Wuxi (Jiangsu Province), and Liuzhou (Guangxi Zhuang Autonomous Region) in the PRC. A total of 730 participants were approached for an interview, of which 27 were unavailable, refused participation, or terminated their interview. In total, 703 (96.4\%) completed the interview and were included in the analysis. The enrollment criteria for the study required that participants must have had one or more of the following types of work-related injury to the fingers, hand, or wrist: laceration, crush, avulsion, puncture, fracture, contusion, amputation, or dislocation. Participants were first screened by clinicians for eligibility and to determine work-relatedness of the injury. After participants signed up to the study, the severity of a hand injury was assessed using the Hand Injury Severity Score (HISS) developed by Campbell et al (14). A HISS score $>50$ was defined as a severe or major injury.

The Fudan School of Public Health Institutional Review Board, the Liberty Mutual Research Institute for Safety Institutional Review Board, and the Harvard School of Public Health Human Subjects Committee approved the study.

\section{Data collection}

We previously reported on the development of our structured questionnaire (15), modeled after the studies by Sorock et al (11), translated into Chinese, and evaluated in the previous pilot study (13). The questionnaire recorded information on 8 self-reported transient expo- 
sures starting at 90 minutes before the onset of the hand injury regarding the participant's work equipment, work practices, and worker- and workplace-related factors. Interviewers trained in human research participant protection, related governmental regulations, informed consent, interview techniques, and questionnaire coding conducted face-to-face interviews. The transient risk factors examined included: (i) using malfunctioning machinery, tools, or work materials; (ii) performing a task with a different method; (iii) performing an unusual work task; (iv) being distracted; (v) rushing; (vi) feeling ill; (vii) working overtime; and (viii) wearing gloves (13).

The usual frequency of exposure in the past workmonth, in which an injury did not occur, was used as control information (10). Information on the 8 transient factors during the 90-minute period (in 10-minute intervals) before the injury was recorded on a worktime-before-injury $\log$ by the interviewer. Participants were asked to estimate the usual frequency and average duration (in minutes or hours) of each episode of exposure to each potential risk factor in the past work week or month. The total exposure to each transient factor was then calculated by multiplying the reported usual frequency by the corresponding average duration of each exposure. Unexposed work time to each transient factor was determined by subtracting the amount of exposed work time in a month from the total amount of time that each subject reported working, including overtime.

\section{Data analysis}

In a case-crossover design, the individually-stratified data are compared using each specific transient exposure's information (yes/no) at the time of injury and the usual duration of each specific exposure in the past month. Therefore, standard methods for stratified analyses were applied in this study $(7,16)$. Relative risk (RR) estimates were based on the ratio of the observed frequency of exposure to each transient factor relative to the expected duration of exposure in the past work month. The average amount of worktime exposed to each factor in the past work month was defined as the control period in the analysis. Participants who reported that an exposure was present at the time of the injury were considered exposed in the analysis. The average incidence rate ratio refers to the rate of having a sudden onset hand injury when exposed to each potential transient risk factor compared to the rate when unexposed. The Mantel-Haenszel estimator for person-time data was used to estimate the RR and $95 \%$ confidence intervals $(95 \% \mathrm{CI})$ for each transient factor (17).

Gender, size of enterprises, and powered machine use were found to affect the risk of hand injury or severity of injury in our pilot study (5). The potential effect modifications of these three fixed factors on the transient factors were evaluated. Chi-square tests of homogeneity were used to test stratification of the potential effect modifiers. Gender was categorized into male and female; powered machine use was either "yes" or "no" at the time of injury; size of enterprises was grouped into " $<100$ employees"(small enterprise) and " $\geq 100$ employees" (large enterprise).

To evaluate the reliability of the self-reported responses to the exposure questions, information on each transient risk factor was obtained at a follow-up interview, within 5 days after the initial interviews with a random sub-sample of 32 participants, and these responses were compared to their initial interviews. To examine the reliability of reported exposure information, a test-retest procedure was conducted. Intra-class correlation coefficients (ICC) were calculated to evaluate the inter-correlation of reported exposures in the past work month. Cohen's kappa coefficient was used to estimate the degree of agreement between the initial and follow-up interviews in reporting each of the exposures to potential risk factors at the time of the injury.

\section{Results}

\section{Worker characteristics}

As shown in table 1, 527 males (75\%) and 176 females participated in this study. The duration from worker injury to interview was a median of 4 (range $0-256$ ) days with $86 \%$ of injured workers being interviewed within 2 weeks of injury. The average age of the study population was 31.5 [standard deviation (SD) 10.3] years. The average age, local residence, and past hand injury experience was not statistically significantly different between males and females. Women were more represented in plastics, food products, textiles and publishing, while men were more represented in machinery, fabricated metal, basic metal and wood products. In addition, in this sample, there were a higher proportion of women working in manufacturing than men $(94 \%$ female versus $82 \%$ male). Less than $32 \%$ of workers had any safety training; $44 \%$ reported having a safety officer supervising their workplace. Most participants were right-handed (98.8\%), $0.8 \%$ were left-handed, and $0.4 \%$ were ambidextrous.

\section{Injury outcomes}

Injuries were relatively evenly split among the right and left hand $(52 \%$ of 750 injuries were to the left hand), with the index finger the most often injured. Crushes (29.7\%) were the most frequent nature of injury, 
Table 1. Descriptive information of hand injured workers, People's Republic of China, October 2004-0ct-2006, N=703. Mean age $=31.8$ (standard deviation 10.3) years. Median age 31 (range 16-62) years.

\begin{tabular}{|c|c|c|c|c|c|c|}
\hline \multirow[t]{2}{*}{ Characteristic } & \multicolumn{2}{|c|}{ Male } & \multicolumn{2}{|c|}{ Female } & \multicolumn{2}{|c|}{ Total } \\
\hline & $\mathrm{N}$ & $\%$ & $\mathrm{~N}$ & $\%$ & $\mathrm{~N}$ & $\%$ \\
\hline Gender & 527 & 75 & 176 & 25 & & \\
\hline \multicolumn{7}{|l|}{ Occupation } \\
\hline Manufacturing & 430 & 81.6 & 166 & 94.3 & 596 & 84.8 \\
\hline Machinery & 124 & 28.8 & 25 & 15.1 & 149 & 25.0 \\
\hline Fabricated metal & 88 & 20.5 & 22 & 13.3 & 110 & 18.5 \\
\hline Motor vehicles & 41 & 9.5 & 16 & 9.6 & 57 & 9.6 \\
\hline Wood products & 34 & 7.9 & 11 & 6.6 & 45 & 7.6 \\
\hline Rubber \& plastics & 29 & 6.7 & 29 & 17.5 & 58 & 9.7 \\
\hline Food products & 15 & 3.5 & 13 & 7.8 & 28 & 4.7 \\
\hline Textiles & 14 & 3.3 & 14 & 8.4 & 28 & 4.7 \\
\hline Other manufacturing a & 85 & 19.8 & 36 & 21.7 & 121 & 20.3 \\
\hline Construction & 43 & 8.2 & 3 & 1.7 & 46 & 6.5 \\
\hline Other & 54 & 10.2 & 7 & 4.0 & 61 & 8.7 \\
\hline \multicolumn{7}{|l|}{ Job experience ${ }^{b}$} \\
\hline$<3$ months & 128 & 24.3 & 52 & 29.5 & 180 & 25.6 \\
\hline 3-12 months & 151 & 28.7 & 52 & 29.5 & 203 & 28.9 \\
\hline $1-5$ years & 159 & 30.2 & 48 & 27.3 & 207 & 29.4 \\
\hline$>5$ years & 87 & 16.5 & 23 & 13.1 & 110 & 15.6 \\
\hline \multicolumn{7}{|l|}{ Safety training } \\
\hline Yes & 175 & 33.2 & 48 & 27.3 & 223 & 31.7 \\
\hline No & 333 & 63.2 & 121 & 68.8 & 454 & 64.6 \\
\hline Do not remember & 19 & 3.6 & 7 & 4.0 & 26 & 3.7 \\
\hline \multicolumn{7}{|l|}{ Safety officer on site } \\
\hline Yes & 242 & 45.9 & 69 & 39.2 & 311 & 44.2 \\
\hline No & 237 & 45.0 & 86 & 48.9 & 323 & 45.9 \\
\hline Do not know & 48 & 9.1 & 21 & 11.9 & 69 & 9.8 \\
\hline \multicolumn{7}{|l|}{ Company size ${ }^{c}$} \\
\hline$<50$ & 280 & 53.6 & 100 & 56.8 & 380 & 54.1 \\
\hline $50-249$ & 144 & 27.6 & 55 & 31.3 & 199 & 28.3 \\
\hline$>250$ & 98 & 18.8 & 21 & 11.9 & 119 & 16.9 \\
\hline
\end{tabular}

a Other manufacturing include manufacturing of basic metals, furniture and publishing/printing.

${ }^{b}$ Missing 3 cases.

${ }^{\mathrm{C}}$ Missing 5 cases.

followed by amputation (25.7\%), fracture (18.5\%), laceration $(12.4 \%)$, avulsion $(7.3 \%)$, contusion $(4.9 \%)$, dislocation $(0.9 \%)$, and puncture $(0.4 \%)$. Severe or major injuries $(65 \%)$ occurred most often while working with food products $(79.2 \%)$, furniture $(72.2 \%)$, non-metallic mineral products $(71.4 \%)$, and wood products $(70.6 \%)$. Powered machines were involved in $59.5 \%$ of injuries. A typical scenario was: "The cutter machine was stuck by a paper roller that just fed in and stopped for a couple of minutes, I tried to remove the paper roller but the cutter was activated suddenly and cut my fingers". Additional descriptive details have been previously published (5).

\section{Exposures}

Six hundred forty nine participants $(92.3 \%)$ reported exposure to at least one transient risk factor at the time of injury, with a total of 1221 exposures or approximately 1.9 exposures per participant on average. Among the participants reporting any exposure during the study case or control periods, 261 participants (37.1\%) reported exposure to only 1 potential risk factor, 255 (36.3\%) to 2 , and $133(18.7 \%)$ to $\geq 3$. The most frequent co-occurring exposure was wearing gloves $(41.4 \%)$. Wearing gloves occurred most often with malfunctioning machine tools or work material $(\mathrm{N}=155)$, performing an unusual work task $(\mathrm{N}=79)$, being rushed $(\mathrm{N}=65)$, performing a task with a different method $(\mathrm{N}=52)$, and being distracted $(\mathrm{N}=43)$.

Work equipment-related exposures were the most frequently reported exposures at the time of injury including wearing gloves $(55 \%)$ and using malfunctioning machinery, tools, or work material (42.8\%). Using malfunctioning machinery, tools or work material, was also associated with the highest RR $(110.4,95 \% \mathrm{CI}$ 97.4-125.2) of hand injury among the eight transient risk factors measured. There was an elevated RR of hand injury $(2.5,95 \% \mathrm{CI} 2.0-3.1)$ when wearing gloves. Performing a task with a different method, performing an unusual work task, and working overtime were three work practice-related exposures. These exposures were associated with a 67.7 -fold, 42.0-fold, and 1.6-fold increase in the RR of hand injury, respectively. Performing an unusual work task was the third most frequently reported exposure at the time of injury $(20.8 \%)$ and performing a task with a different method was the fifth $(14.2 \%)$, while working overtime was reported less frequently $(8.3 \%)$. Being distracted, rushing, and feeling ill were considered worker-related exposures. All three exposures were significantly associated with the occurrence of hand injury (table 2). With respect to person-time exposed in the prior month, the transient risk factors with the highest percentages of time exposed were wearing gloves $(53.5 \%)$, working overtime $(4.5 \%)$ and being rushed $(3.1 \%)$, see figure 1 .

In work-equipment-related exposures, 301 participants reported using malfunctioning machinery, tools, or work materials. Of these, $39 \%$ were attributed to the tool/

Table 2. Transient exposures and relative risk (RR) of work-related acute traumatic hand injury, People's Republic of China, October 2004-0ct-2006. [95\% Cl=95\% confidence interval.]

\begin{tabular}{|c|c|c|c|c|}
\hline $\begin{array}{l}\text { Transient } \\
\text { exposure }\end{array}$ & $\begin{array}{c}\text { Exposed at } \\
\text { the time of } \\
\text { injury }\end{array}$ & $\begin{array}{l}\text { Exposed in } \\
\text { the prior } \\
\text { month }\end{array}$ & $\mathrm{RR}$ & $95 \% \mathrm{Cl}$ \\
\hline Unusual performa & 301 & 232 & 110.42 & $97.38-125.21$ \\
\hline Unusual task & 146 & 103 & 52.34 & $41.98-65.26$ \\
\hline Unusual method & 100 & 48 & 84.34 & $67.68-105.11$ \\
\hline Feeling sick & 24 & 36 & 14.24 & $8.64-23.46$ \\
\hline Rushed & 121 & 114 & 33.64 & $24.78-45.66$ \\
\hline Distracted & 84 & 42 & 69.62 & $57.87-83.74$ \\
\hline Over time & 58 & 249 & 2.08 & $1.57-2.74$ \\
\hline Gloves & 387 & 399 & 2.51 & $2.02-3.11$ \\
\hline
\end{tabular}

a Indicates unusually performing or malfunctioning equipment. 


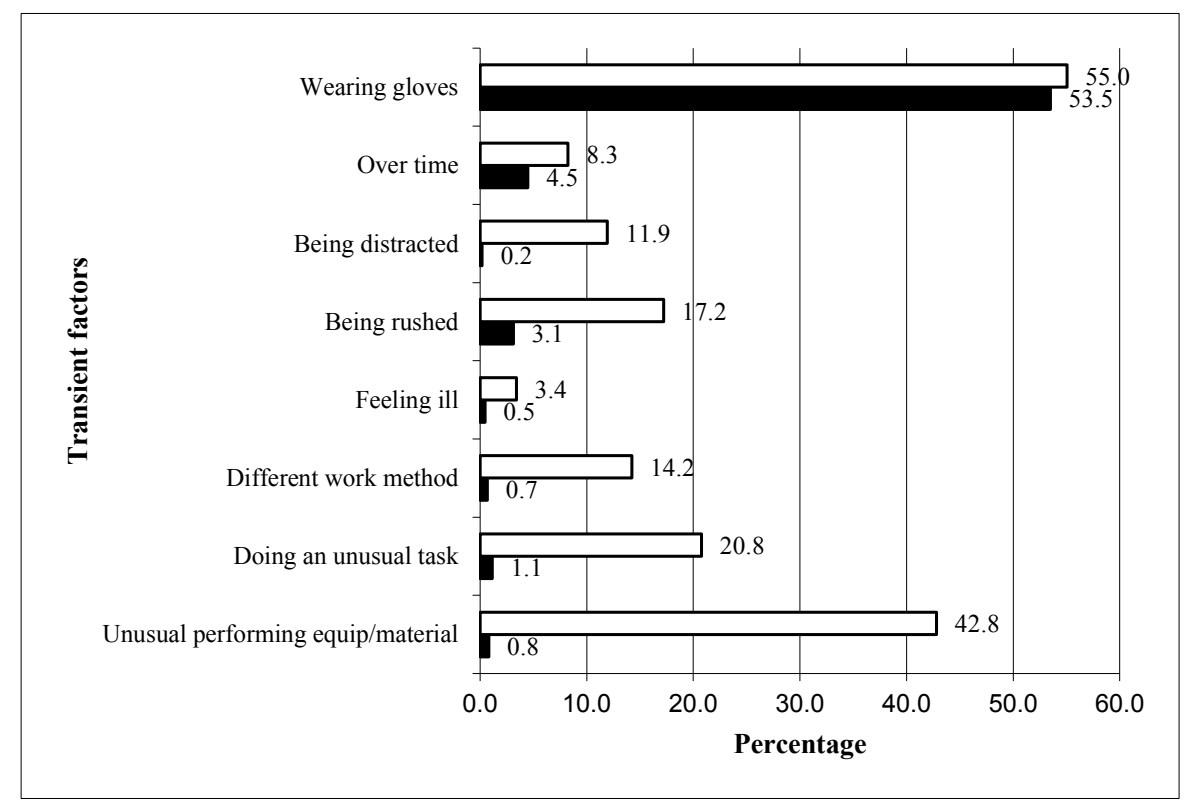

Figure 1. Percentage of subjects exposed to each of the eight transient risk factors at the time of the injury (white bars) compared to the average percentage of total person-time at work exposed to each risk factor in the month prior to the injury (black bars). For example, $42.8 \%$ of injured worker were exposed to using malfunctioning machine, tools, or work material at the time of the injury, but participants reported being exposed to this transient factor $0.8 \%$ of work time in the previous month. machine not performing as expected, $21 \%$ to an unusual work piece, $17 \%$ to a jammed machine, $13 \%$ were unclassified, $6 \%$ to lost communication with co-worker, and 3\% to accidentally hitting a switch. In work-practice exposures, 146 participants reported performing an unusual work task, including putting the hand in unusual position $(24 \%)$, unjamming (16), hammering or pressing task $(16 \%)$, material handling $(15 \%)$, machine maintenance $(11 \%)$, and cutting $(8 \%)$. One hundred participants reported performing a task with a different method, including using a different tool or operation (36\%), putting a hand in an unusual position (28\%), unusual work piece (23\%), and being close to blade (6\%); $7 \%$ were not categorized. In worker-related exposure, the leading reasons for rushing $(\mathrm{N}=121)$ included working quickly to get the current job done $(30 \%)$, being rushed by supervisor or customer $(25 \%)$, preparing to go home $(12 \%)$, catching up with backed-up work (8\%), being understaffed $(3 \%)$, and other time pressures or emergencies $(21 \%)$. The leading reasons for being distracted $(\mathrm{N}=84)$ included thinking about non-work tasks (26\%), talking/looking to a co-worker (20\%), fatigue (15\%), and other external (10\%) or internal $(29 \%)$ distractions.

\section{Effect of gender, powered machine, and size of enterprise}

Workers in small enterprises ( $<100$ employees) and female workers had increased RR compared to those in large enterprises and male workers, respectively. While the RR for powered machines were higher when using gloves, being sick, rushing, and being distracted, these differences were not statistically significant (table 3).

\section{Reliability assessment}

In the reliability sub-study, 35 participants were invited to be re-interviewed at the initial interview using the original questionnaire. Of the randomly selected participants, 32 completed the second interview while 3 declined participation. Of those who completed the second interview, most were re-interviewed within 5-7 days of the first interview, except for one case who was re-interviewed after 18 days.

In reporting exposures to transient risk factors at the time of injury, kappa values for being rushed, working overtime, performing an unusual work task, wearing gloves, and using malfunctioning machinery, tools, or work material showed high levels of agreement $(>0.75)$. Performing a task with a different method had a kappa of 0.64 which indicates substantial agreement between the two interviews. Reports of being distracted had the lowest reliability, and exposure to feeling sick could not be calculated due to zero values in cells. In reporting average exposure hours to transient risk factors in the prior work-month, exposures to using malfunctioning machinery, tools, or work materials, performing task with a different method, working overtime, and wearing gloves showed the highest reliability with ICC $>0.9$ between the two interviews; exposures to feeling sick showed fair reliability with ICC $>0.8$. Other exposures, like performing an unusual work task, being distracted, or rushing showed the lowest reliability (ICC range: $0-0.05)$. 
Table 3. Relative risks (RR) of hand injury for transient factors stratified by selected worker/workplace characteristics, People's Republic of China. $[95 \% \mathrm{Cl}=95 \%$ confidence interval. $]$

\begin{tabular}{|c|c|c|c|c|c|c|c|c|c|c|c|c|c|c|}
\hline & \multicolumn{2}{|c|}{ All subjects } & \multicolumn{2}{|r|}{ Male } & \multicolumn{2}{|r|}{ Female } & \multicolumn{2}{|c|}{$\begin{array}{l}\text { Powered } \\
\text { machine }\end{array}$} & \multicolumn{2}{|c|}{$\begin{array}{l}\text { Non-powered } \\
\text { machine }\end{array}$} & \multicolumn{2}{|c|}{$\begin{array}{c}\text { Small } \\
\text { enterprises }\end{array}$} & \multicolumn{2}{|c|}{$\begin{array}{l}\text { Large } \\
\text { enterprises }\end{array}$} \\
\hline & $\mathrm{RR}$ & $95 \% \mathrm{Cl}$ & $\mathrm{RR}$ & $95 \% \mathrm{Cl}$ & $\mathrm{RR}$ & $95 \% \mathrm{Cl}$ & $\mathrm{RR}$ & $95 \% \mathrm{Cl}$ & $\mathrm{RR}$ & $95 \% \mathrm{Cl}$ & $\mathrm{RR}$ & $95 \% \mathrm{Cl}$ & $\mathrm{RR}$ & $95 \% \mathrm{Cl}$ \\
\hline \multicolumn{15}{|l|}{$\begin{array}{l}\text { Work } \\
\text { equipment }\end{array}$} \\
\hline $\begin{array}{l}\text { Unusual } \\
\text { performance }\end{array}$ & 110.4 & $97.4-125.2$ & 86.3 & $76.8-97.0$ & 404.5 & $218.2-749.8$ & 88.4 & $77.3-101.1$ & $-b$ & $-b$ & 87.2 & $76.7-99.2$ & 199.2 & $142.7-278.0$ \\
\hline $\begin{array}{l}\text { Glove use } \\
\text { Work } \\
\text { practice }\end{array}$ & 2.5 & $2.0-3.1$ & 2.9 & $2.3-3.7$ & $9.0^{\mathrm{a}}$ & $3.3-24.3$ & 5.2 & $3.7-7.4$ & 1.5 & $1.2-2.0$ & $4.2^{\mathrm{a}}$ & $3.1-5.6$ & 2.2 & $1.5-3.2$ \\
\hline $\begin{array}{l}\text { Unusual } \\
\text { method }\end{array}$ & 84.3 & $67.7-105.1$ & 58.9 & $46.6-74.3$ & $-b$ & $-b$ & 60.9 & $47.1-78.7$ & $-b$ & $-b$ & 50 & $38.6-64.8$ & $-b$ & $-b$ \\
\hline $\begin{array}{l}\text { Unfamiliar } \\
\text { task }\end{array}$ & 52.3 & $42.0-65.3$ & 43.7 & $34.4-55.5$ & 115.7 & $62.0-215.9$ & 43.1 & $33.7-55.2$ & 128.2 & $72.9-225.2$ & 41.7 & $32.1-54.2$ & 90.6 & $58.7-140.0$ \\
\hline Over time & 2.1 & $1.6-2.7$ & 2 & $1.5-2.8$ & 2.4 & $1.4-4.3$ & 2 & $1.5-2.7$ & 2.9 & $1.6-5.3$ & 2.5 & $1.8-3.5$ & 1.4 & $0.9-2.4$ \\
\hline \multicolumn{15}{|l|}{$\begin{array}{l}\text { Worker- } \\
\text { related factors }\end{array}$} \\
\hline Being sick & 14.2 & $8.6-23.5$ & 12.9 & $7.7-21.6$ & 28.7 & $7.7-106.3$ & 36 & $16.8-77.2$ & 4.5 & $2.0-10.3$ & 12.5 & $6.6-23.4$ & 31.5 & $13.9-71.6$ \\
\hline Rushed & 33.6 & $24.8-45.7$ & 30.3 & $20.7-44.4$ & 41.9 & $24.6-71.4$ & 42.5 & $29.3-61.7$ & 17.1 & $9.3-31.6$ & 43.1 & $27.8-66.8$ & 21 & $13.8-31.9$ \\
\hline Distracted & 69.6 & $57.9-83.7$ & 49.5 & $40.4-60.8$ & $-b$ & $-b$ & 74.8 & $61.9-90.4$ & 50.8 & $28.4-90.9$ & 264.815 & 192.1-365.0 & 23 & $17.1-30.9$ \\
\hline
\end{tabular}

\section{Discussion}

The study population in this report was relatively young (mean age 32 years), predominantly male (75\%), worked in manufacturing industries (70\%), and in smaller scale industries (54\% in companies with $<50$ employees). Our sampling strategy required that participants had been hospitalized due to hand injury. Using the Hand Injury Severity Scoring (5), 65\% of these hand injuries were categorized as "severe" or "major". We utilized the case-crossover design to assess if the injury may have been "triggered" by one or more transient risk factors that occurred just prior to the injury. The same protocol was used as in a North American study by Sorock et al (11) and Lombardi et al (9) and in Hong Kong, China, by Chow et al (12).

In these prior studies, wearing gloves was identified as a protective factor that was significant in Sorock et al's report (11) (RR 0.4, 95\% CI 0.3-0.8) but insignificant in Chow et al's (RR 0.7, 95\% CI 0.38-1.34). However, in the current study, wearing gloves showed a RR of 2.5 (95\% CI 2.0-3.1), indicating that wearing gloves was associated with an elevated risk of a hand injury in our study population. Although inconsistent with prior studies, there are several possible explanations for this finding including: (i) greater exposure to heavy energized machines and systems in the current population than the populations examined in the other two studies. The more severe injuries (eg, crushes) evidenced in the current population could indicate greater exposure to higher energy risks. Gloves do not protect workers from injury by high energy external forces. In the Sorock et al report (18), for example, glove use was not associated with a reduced relative risk of crush, avulsion, amputation, or fracture injuries to the fingers or hand (RR 0.93 , 95\% CI 0.62-1.39) but was associated with a reduced RR of a laceration injury [lacerations accounted for $63 \%$ of all injuries in the Sorock et al report (11)]; (ii) wearing gloves may also reduce operational flexibility and could actually cause a gloved hand to be caught in moving machinery; and (iii) wearing gloves might be confounded by other cooccurring risk factors. The last point has been referred to as multiple-correlated transient factors (19), for example, wearing gloves occurred most often with malfunctioning machine tools or work material, performing an unusual work task, being rushed, and performing a task with a different method. Another possibility is that workers sometimes wear incorrectly sized gloves. Hsu et al (20) reported Taiwanese hand-surface areas (HSA) show significance in gender difference (male mean HSA 155.3, SD 17.5, $\mathrm{cm}^{2}$; female mean HSA 128.4, SD 18.5, $\mathrm{cm}^{2}$ ) using a high-resolution 3D hand scanner suggesting that female workers may be likely to wear over-sized gloves (20). Use of over-sized gloves may increase the hazard of being caught by excess glove material in moving machinery (see table 3 ). Proper sizing of gloves for men and women may need greater attention in industrial settings, especially for female workers as our data suggested women working with gloves had higher chance of hand injuries.

Other transient risk factors showed strong associations with occurrence of hand injury. The RR value 
varied from 110.4 (using malfunctioning machinery, tools, or work material, 95\% CI 97.4-125.2) to 2.08 (working overtime, 95\% CI 1.6-2.7). To further understand the impact of the malfunctioning machinery/tools on the absolute risk of workplace injury, one must consider the baseline risk of injury, the frequency of exposure to the transient risk factor, and the RR associated with it. For example, participants in this study reported working with malfunctioning equipment for $0.85 \%$ of their work time in last work month. Assuming that the average monthly risk of an acute hand injury at work is $5.0 \%$ in small enterprises and the RR associated with working with unusual-performing equipment among workers in this industry is 87.2 , we can estimate the absolute risk as $(0.9915 \times 5 \%)+(0.0085 \times 5 \% \times 87.2)$ $=8.7 \%$. Thus, under these assumptions, the average monthly absolute excess risk associated with working with malfunctioning equipment would be $3.7 \%$ in populations of workers with a similar distribution of transient exposures.

Our findings regarding using malfunctioning machinery, tools, or work material were similar to those of Chow et al (12) and Sorock et al (10). This suggests that maintenance or regular checking of machines or tools involving hand operation should be a high priority in controlling work-related acute traumatic hand injuries. In comparing the size of the RR across studies, the results of the current study showed generally higher RR relative to both the Chow et al (12) and the Sorock et al (10) studies. The difference in reported RR values of transient risk factors may reflect differences among the studied populations and the working conditions. In the Sorock et al study (10), the participants were recruited from occupational clinics and primarily reported minor injuries; the Chow et al study (12) enrolled participants from among injured workers making claims for occupational compensation for hand injuries. In our study, participants had been hospitalized as a result of their hand injury and, consequently, tended to have more severe injuries than the other two studies. Although reliability results were generally strong for all exposures, the size of the RR in this study may also be the result of participants underestimating exposures in the prior work month (control period) due to the limited ability to recall exposure information over a longer period of time. Perhaps just as likely, the workers in this study might have over-reported exposure at the time of the injury. For example, the percent exposed to an unusual task at the time of the injury and at any time in the past month were $21 \%$ and $15 \%$, respectively, for the injured Chinese workers and $11 \%$ and $31 \%$, respectively, for the injured US workers. The results of the reliability sub-study suggest the consistency of reporting over time. Reliability in reporting exposures at the time of injury showed good or very good agreement between initial and follow-up interview for most of the exposures and low agreement for exposure to being distracted. This finding on distraction also had the lowest ICC of any transient risk factor in the Lombardi et al report (21) suggesting that distraction may be hard to reliably recall at the time of the injury. The possible explanations of low ICC may reflect the less organized working environment among the injured workers in this study for example, a pile of unorganized working material may catch a passing-by co-worker and create a distraction to the nearby workstation.

Regarding exposure to malfunctioning machinery, the largest RR identified in the current study were associated with unexpected movement of tool or machine (eg, circular saw run in reverse direction), unusual work piece (eg, cutting through a knot in wood piece) and jammed machine. Proper warnings and relative locking mechanisms to prevent human body part involvement in the danger area (such as points of operation or power transmission) are stated in the general national guideline on machinery safety $(5.2 .4$ GB/T15706.2-2007 as a Chinese version of ISO121002:2003) from the China National Standardization Technical Committee for Safety of Machinery (22). A detailed lock- and tag-out procedure can be found in the chemical industrial standard of safety management protocol for facility maintenance (HG/T 23008-92). It should be noted that the above regulations are NOT mandatory (which would show a " $\mathrm{T}$ " in the assigned serial number). The current results suggest the potential value of adopting a standard such as Control of Hazardous Energy - Lockout/Tagout and Alternative Methods (ANSI/ASSE Z244.1-2003) for improved machine safety for workers in the PRC.

\section{Concluding remarks}

This study identified eight modifiable transient risk factors for an acute traumatic hand injury among Chinese workers. These include: (i) using malfunctioning machinery, tools, or work material; (ii) performing a task with a different method; (iii) performing an unusual work task; (iv) being distracted; (v) rushing; (vi) feeling ill; (vii) working overtime; and (viii) wearing gloves. Regular maintenance of machine or tools involving hand operation is a high priority to control acute traumatic hand injury. Safety officers should give a high priority to worker training on how to protect the hands when machinery, tools, or work materials malfunction. More research on why gloves may increase the risk of hand injury is also needed. 


\section{Acknowledgements}

The authors are grateful to Drs Mary Lesch and Yulan Liang for their comments on the draft of this paper. We also thank Liuzhou Municipal Center for Disease Control and Prevention, Ningbo No 6 Hospital, and Wuxi Municipal Center for Disease Control and Prevention for providing resources.

This study was supported by the Liberty Mutual Research Institute for Safety and the Guangxi Science Foundation, People's Republic of China (No. 0542114). It was conducted during Dr. Jin's tenure as a post-doctoral research fellow at the Harvard School of Public Health and the Liberty Mutual Research Institute for Safety.

\section{References}

1. Hertz RP, Emmett EA. Risk factors for occupational hand injury. J Occup Med. 1986 Jan;28(1):36-41. http://dx.doi. org/10.1097/00043764-198601000-00010.

2. Serinken M, Karcioglu O, Sener S. Occupational hand injuries treated at a tertiary care facility in western Turkey. Ind Health. 2008Jul;46(3): 239-46. http://dx.doi.org/10.2486/ indhealth.46.239.

3. Akram M, Awais SM, Rabiulislam M, Hanif A. Occupational Hand Injuries Presenting at Accident and Emergency Department/Mayo Hospital Lahore. A Review of Six Months. Annals of KEMU. 2010;16(1 SI):3.

4. Lai CH, Tsui KL, Kam CW. Work-related crushing injuries with amputations of digits, hands and forearms. Hong Kong J Emerg Med. 2007;14(1):7.

5. Jin K, Lombardi D, Courtney T, Sorock G, Li M, Pan R, Wang X, Lin J, et al. Patterns of work-related traumatic hand injury among hospitalised workers in the People's Republic of China. Inj Prev. 2010 Feb;16(1):42-9. http://dx.doi.org/10.1136/ip.2008.019737.

6. Peng F, Chen L, Zhao G, Zhang W, Gu Y. Industrial Hand Injuries by Presses Machine: A Case-control Study. National Med J China. 2002;82(18):1257-60.

7. Maclure M. The Case-Crossover Design: A Method for Studying Transient Effects on the Risk of Acute Events. Am J Epidemiol. 1991 January 15, 1991;133(2):144-53.

8. Maclure M, Mittleman MA. Should we use a case-crossover design? Annu Rev Public Health. 2000;21:193-221. http://dx.doi.org/10.1146/annurev.publhealth.21.1.193.

9. Lombardi DA, Sorock GS, Holander L, Mittleman MA. A casecrossover study of transient risk factors for occupational hand trauma by gender. J Occup Environ Hyg. 2007;4(10):790-7.

10. Sorock GS, Lombardi DA, Hauser R, Eisen EA, Herrick
RF, Mittleman MA. A case-crossover study of transient risk factors for occupational acute hand injury. Occup Environ Med. 2004 Apr;61(4):305-11. http://dx.doi.org/10.1136/ oem.2002.004028.

11. Sorock GS, Lombardi DA, Hauser RB, Eisen EA, Herrick RF, Mittleman MA. A case-crossover study of occupational traumatic hand injury: methods and initial findings. Am J Ind Med. 2001;39(2):171-9.

12. Chow CY, Lee H, Lau J, Yu IT. Transient risk factors for acute traumatic hand injuries: a case-crossover study in Hong Kong. Occup Environ Med. 2007 Jan;64(1):47-52. http://dx.doi. org/10.1136/oem.2006.028589.

13. Jin K, Lombardi DA, Courtney TK, Sorock GS, Perry MJ, $\mathrm{Chen} \mathrm{H}$, et al. The challenge of cross-cultural collaborative research: lessons learnt from a pilot case-crossover study of severe occupational hand trauma in the People's Republic of China. Inj Prev. 2007 Apr;13(2):133-6. http://dx.doi. org/10.1136/ip.2006.012534.

14. Campbell DA, Kay SP. The Hand Injury Severity Scoring System. J Hand Surg [Br]. 1996 Jun;21(3):295-8. http:// dx.doi.org/10.1016/S0266-7681(05)80187-1.

15. Jin K, Sorock GS, Courtney TK. Prevalence of low back pain in three occupational groups in Shanghai, People's Republic of China. J Safety Res. 2004;35(1):23-8. http://dx.doi. org/10.1016/j.jsr.2003.11.002.

16. Mittleman MA, Maclure M, Robins JM. Control Sampling Strategies for Case-Crossover Studies: An Assessment of Relative Efficiency. Am J Epidemiol. 1995 July 1,1995;142(1):91-8.

17. Rothman K, S. G. Modern epidemiology. 2nd ed. Philadelphia, PA: Lippincott-Raven Publishers; 1998.

18. Sorock GS, Lombardi DA, Peng DK, Hauser R, Eisen EA, Herrick RF, Mittleman MA. Glove use and the relative risk of acute hand injury: a case-crossover study. J Occup Environ Hyg. 2004 Mar;1(3):182-90.

19. Sorock GS, Lombardi DA, Gabel CL, Smith GS, Mittleman MA. Case-crossover studies of occupational trauma: methodological caveats. Inj Prev. 2001 Sep;7 Suppl 1:i38-42. http://dx.doi.org/10.1136/ip.7.suppl_1.i38.

20. Hsu YW, Yu CY. Hand surface area estimation formula using 3D anthropometry. J Occup Environ Hyg. 2010 Nov; 7(11): 633-639. http://dx.doi.org/10.1080/15459624.2010.514259.

21. Lombardi DA, Sorock GS, Lesch MF, Hauser R, Eisen EA, Herrick RF, Mittleman MA. A reliability study of potential risk factors for acute traumatic occupational hand injuries. Am J Ind Med. 2002;42(4):336-43.

22. National Standardation Technical Committee for Safety of Machinery, Standards Press of China. Machinery Safety Standards. Beijing: Standards Press of China; 2007.

Received for publication: 7 July 2011 